\title{
An Evolutionary Perspective on Cardiovascular Disease
}

\section{Dan Yang and Zhihua Liu*}

Department of Computational Biology and Bioinformatics, Institute of Medicinal Plant Development, Chinese Academy of Medical Sciences and Peking Union Medical College, Beijing 100193, China

\section{Editorial}

Evolutionary biology widely accepted as providing the ultimate foundation for biology and hence for the health sciences has occupied a position within the health sciences from a distant perspective $[1,2]$. "Survival of the fittest" is the core idea of the theory of evolution. The evolution of the human species is not in itself be the pink of perfection, but is a continuous "adaptation" and breeding process [3]. In the late 90's, a new subject arises in the west-evolutionary medicine which combine the concepts of evolutionary biology and medical science [4]. The subject of evolutionary medicine mainly has three aspects. Firstly, evolution is not equal to make advantageous progress, which actually involves both positive and negative side; secondly, disease is the result of interaction between man and nature, to study which, four-dimensional space-time evolution (emphasize the time factor) should be considered. Thirdly, the disease itself is also in continuous evolutionary processes, and comply with natural selection law -- die, strengthen or variation [5-7].

The cardiovascular system has very poorly regeneration ability, and plays a crucial role in various physiological homeostasis in the body [8,9]. Cardiovascular disease is a complex, multifactor disease that involves complex interactions among multiple genetic and environmental conditions [10,11]. Although modern medical research has carried out on the pathogenesis and prevention of this kind of disease by using advanced techniques, and made great progress [12-14], like other branches of medicine, people only notice the recent cause of this kind of disease, carry out few studies on the original cause from the whole evolutional processes.

To make a fully understanding of this kind of civilized social disease, people must place cardiovascular disease in a view of the evolution of human civilization history. Cardiovascular disease derives from the degeneration of evolution in development to the man civilization [1517]. The human civilization spends a mere 10,000 years, only a minimal part throughout the history of human development, but its occurrence turns the human world upside down. Our body is designed by nature after millions of years of natural selection. However, there is no enough time for natural selection to change this design of the body to adapt us to the lifestyle of the modern society, such as high fat diet, excessive energy intake corresponding to the low body consumption, excessive alcohol and tobacco consumption, fast pace of life and excessive psychological pressure, all of which are the main risk factors of cardiovascular disease [18]. Studies suggest that the pathogenesis of cardiovascular disease involves many genetic problems [19-21]. Some genes dominate the phenotypes which are useful in ancient environments, such as storage of fat [15]; some are harmless in the ancient environment, however harmful when combined with the life style of the modern society, such as obesity, hypertension and diabetes [15]; also, some are multi-function, which will be retained by natural selection when its benefits over its harmful effects on the human body, such as upregulation of blood pressure in adolescence and the phenotypes during the formation of the arterial wall atherosclerosis, including calcium deposition, fibrous tissue proliferation and wound repair [22,23]. These genes are retained by natural selection, because they are in favor of human germline reproduction [24]. Thus, cardiovascular disease is the historical problem left behind by natural design.
Modern medicine has put forward various methods of prevention and treatment of cardiovascular disease, such as gene therapy, an experimental technique which targets genes to treat or prevent disease. Nowadays, gene therapy is popular over the world. Actually, a lot of risk factors of cardiovascular disease have their own genetic basis. However, from an evolutionary perspective, natural evolution is chaotic, no purpose, no direction, and the law of natural selection may not be perfect but orderly. People artificially accelerate the speed of natural selection, for example by transforming our body through gene engineering to adapt us to this humanistic environment, however, the problem is that the so-called perfect process may lead to disorder out of control [22]. One of the most important problems is that when we change one or a group of genes which we consider defective, such as some genes associated with immune response or inflammation under the condition of coronary heart disease, we are unable to discern whether these genes have some other beneficial effects for the human body. At the same time, other treatment modalities, such as control of obesity, the use of antioxidants and change of diet structure, left behind similar problems. Simply put, cardiovascular system can not guarantee coordination between the long-term design of the body by nature and the short-term creation of cultural environment by us.

Evolutionary considerations of cardiovascular disease provide us a comprehensive view to understand this kind of complex disease such as atherosclerosis and hypertension. We expect evolutionary medicine will become a mainstream medical science in this century, and set up a new medical revolution to unravel the very essence of cardiovascular disease.

\section{Acknowledgement}

This work was supported by National Natural Science Foundation of China (81102746, 81100077, 31201768), Beijing Natural Science Foundation (5113033), Scientific Research Foundation of the State Human Resource Ministry and the Education Ministry for Returned Chinese Scholars, New Star Project of Peking Union Medical College, Outstanding Youth Scrolling Foundation of Peking Union Medical College, Basic Scientific Research Operation Cost of State-Leveled Public Welfare Scientific Research Courtyard (YZ-12-15), Special Foundation of China Postdoctoral Science (2012T50067), China Postdoctoral Science Foundation (2011M500014, 2012M510011), the Research Fund for the Doctoral Program of Higher Education (20111106120028), "Major Drug Discovery" major science and technology research "12nd Five-Year Plan" (2012ZX09301-002-001-025), China Medical Board of New York (A2009001), Program for New Century Excellent Talents in University (NCET) granted to Zhihua Liu.

\section{References}

1. Sommer RJ, McGaughran A (2013) The nematode Pristionchus pacificus as a model system for integrative studies in evolutionary biology. Mol Ecol 22 . 2380-2393.

*Corresponding author: Zhihua Liu, Department of Computational Biology and Bioinformatics, Institute of Medicinal Plant Development, Chinese Academy of Medical Sciences and Peking Union Medical College, Beijing 100193, China, E-mail: zhliu@implad.ac.cn, zhliu.liulab@foxmail.com

Received June 20, 2013; Accepted June 24, 2013; Published June 26, 2013

Citation: Yang D, Liu Z (2013) An Evolutionary Perspective on Cardiovascular Disease. J Phylogen Evolution Biol 1: e103. doi:10.4172/2329-9002.1000e103

Copyright: ( 2013 Yang D, et al. This is an open-access article distributed under the terms of the Creative Commons Attribution License, which permits unrestricted use, distribution, and reproduction in any medium, provided the original author and source are credited. 
Citation: Yang D, Liu Z (2013) An Evolutionary Perspective on Cardiovascular Disease. J Phylogen Evolution Biol 1: e103. doi:10.4172/2329-

2. Noble D (2013) Physiology is rocking the foundations of evolutionary biology Exp Physiol.

3. Yokoyama S (2012) Synthesis of Experimental Molecular Biology and Evolutionary Biology: An Example from the World of Vision. Bioscience 62: 939-948.

4. Stearns SC (2012) Evolutionary medicine: its scope, interest and potential. Proc Biol Sci 279: 4305-4321.

5. Joseph PG, Pare G, Anand SS (2013) Exploring gene-environment relationships in cardiovascular disease. Can J Cardiol 29: 37-45.

6. Nesse RM, Bergstrom CT, Ellison PT, Flier JS, Gluckman P, et al. (2010) Evolution in health and medicine Sackler colloquium: Making evolutionary biology a basic science for medicine. Proc Natl Acad Sci USA 107: 1800-1807.

7. Nesse RM (2008) What evolutionary biology offers public health. Bull World Health Organ 86: 83.

8. Re RN (1988) Emerging issues in the cellular biology of the cardiovascular system. Am J Cardiol 62: 7G-12G.

9. Bibliography (2002) Current world literature. Cardiovascular system. Curr Opin Crit Care 8: 473-491.

10. Waksman R (2013) Innovation: a key to success in the treatment of cardiovascular disease. Cardiovasc Revasc Med 14: 121.

11. Madrigal-Matute J, Martin-Ventura JL, Blanco-Colio LM, Egido J, Michel JB et al. (2011) Heat-shock proteins in cardiovascular disease. Adv Clin Chem 54: $1-43$.

12. Pines A (2011) Vasomotor symptoms and cardiovascular disease risk. Climacteric 14: 535-536.

13. Houston MC (2011) Role of mercury toxicity in hypertension, cardiovascular disease, and stroke. J Clin Hypertens (Greenwich) 13: 621-627.
14. North BJ, Sinclair DA (2012) The intersection between aging and cardiovascular disease. Circ Res 110: 1097-1108.

15. Archer E, Blair SN (2011) Physical activity and the prevention of cardiovascular disease: from evolution to epidemiology. Prog Cardiovasc Dis 53: 387-396.

16. Beiser EN (1990) Reporting physicians' mistakes. R I Med J 73: 333-344.

17. deGoma EM, Knowles JW, Angeli F, Budoff MJ, Rader DJ (2012) The evolution and refinement of traditional risk factors for cardiovascular disease. Cardiol Rev 20: 118-129.

18. Devereux RB, Alderman MH (1993) Role of preclinical cardiovascular disease in the evolution from risk factor exposure to development of morbid events. Circulation 88: 1444-1455.

19. Sobieszczanska M, Jonkisz J, Tabin M, Laszki-Szczachor K (2013) Osteoporosis: genetic determinants and relationship with cardiovascular disease. Adv Clin Exp Med 22: 119-124.

20. Webster AL, Yan MS, Marsden PA (2013) Epigenetics and cardiovascular disease. Can J Cardiol 29: 46-57.

21. McPherson R (2013) From genome-wide association studies to functiona genomics: new insights into cardiovascular disease. Can J Cardiol 29: 23-29.

22. Nesse RM (2001) How is Darwinian medicine useful? West J Med 174: 358 360 .

23. Williams GC, Nesse RM (1991) The dawn of Darwinian medicine. Q Rev Biol 66: 1-22.

24. Nesse RM (2001) On the difficulty of defining disease: a Darwinian perspective. Med Health Care Philos 4: 37-46. 